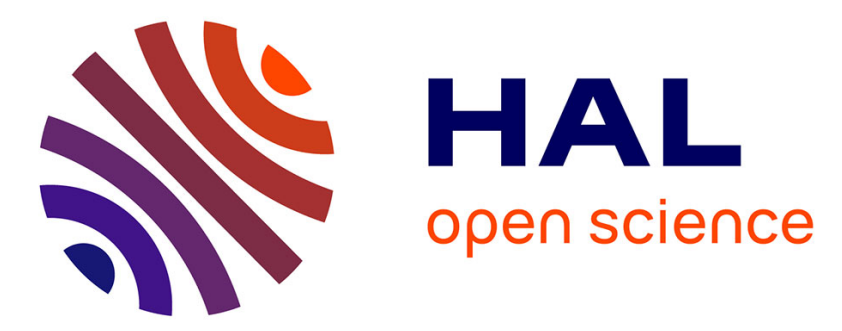

\title{
Recurrent posttraumatic trapeziometacarpal joint dislocation in a child: A case report
}

Jérémy Gaillard, Franck Fitoussi

\section{To cite this version:}

Jérémy Gaillard, Franck Fitoussi. Recurrent posttraumatic trapeziometacarpal joint dislocation in a child: A case report. Hand Surgery and Rehabilitation, 2016, 35 (2), pp.139-143. 10.1016/j.hansur.2015.12.009 . hal-01358335

\section{HAL Id: hal-01358335 \\ https://hal.sorbonne-universite.fr/hal-01358335}

Submitted on 31 Aug 2016

HAL is a multi-disciplinary open access archive for the deposit and dissemination of scientific research documents, whether they are published or not. The documents may come from teaching and research institutions in France or abroad, or from public or private research centers.
L'archive ouverte pluridisciplinaire HAL, est destinée au dépôt et à la diffusion de documents scientifiques de niveau recherche, publiés ou non, émanant des établissements d'enseignement et de recherche français ou étrangers, des laboratoires publics ou privés. 


\section{TITLE PAGE}

\section{RECURRENT POST TRAUMATIC TRAPEZIOMETACARPAL JOINT DISLOCATION IN A CHILD: A CASE REPORT}

J. Gaillard, F. Fitoussi (MD/Phd)

Julien_gaillard94@hotmail.com

Franck.fitoussi@trs.aphp.fr

Study conduct at Trousseau Hospital, Orthopaedic and Reconstructive Paediatric Surgery Department, Paris 6 University, Paris, France 26, avenue du Dr Arnold Netter, 75012 Paris

Corresponding author: Julien_gaillard94@hotmail.com

KEYWORDS: trapeziometacarpal joint; dislocation; thumb; instability; child MOTS CLES: articulation trapézo-métacarpienne, luxation, pouce, instabilité, enfant 


\section{SUMMARY}

A traumatic trapeziometacarpal joint dislocation of the thumb accounts for less than $1 \%$ of all hand injuries. This lesion is even less frequent in children. Optimal treatment strategies for this injury are still a subject of debate for both children andadults. In this article, we report a case of recurrent post traumatic trapeziometacarpal joint dislocation for an eight-year old girl. Regarding the English literature we believe our case is the first report of recurrent acute dislocation, leading to chronic dislocation. Restoring the anatomy and biomechanics of the trapeziometacarpal joint is essential when treating these injuries, and that is why surgical treatment is usually indicated. Overall, the prognosis of trapeziometacarpal dislocation treated acutely is favourable and stable over time. The role of open surgery and ligamentoplasty remains controversial, especially in children.

\section{RESUME}

La luxation de l'articulation trapézo-métacarpienne compte pour moins de 1\% des traumatismes de la main. Cette lésion est encore plus rarement observée chez les enfants. Le traitement optimal de ce traumatisme reste controversé chez l'enfant, comme chez l'adulte. Cet article rapporte le cas d'une luxation itérative de l'articulation trapézo-métacarpienne chez une enfant de 9 ans. Au regard de la littérature, il semblerait que cela soit le premier cas de luxation itérative, conduisant à une instabilité chronique. Restaurer l'anatomie et la biomécanique de l'articulation trapézo-métacarpienne est essentiel lors de la prise en charge de ces traumatismes, et c'est la raison pour laquelle le traitement chirurgical est indiqué. Les luxations trapézo-métacarpiennes prises en charge précocement sont généralement de bon pronostic, avec une évolution stable au fil du temps. Le rôle de la ligamentoplastie reste controversé, particulièrement chez l'enfant. 


\section{INTRODUCTION}

Isolated traumatic dislocation of the thumb carpometacarpal joint, also called the trapeziometacarpal (TMC) joint, is a rare injury and accounts for less than $1 \%$ of all hand injuries [1]. Acute TMC dislocation and TMC instability are even less frequent in children. McLaughlin and Abouzhar were the first to report TMC dislocation in a child [2]. Varitimidis and Sotereanos described the case of a volar oblique ligament reconstruction for carpometacarpal joint dislocation in an 11-year-old [3], whereas Rashdeen et al. presented the first case of a child with simultaneous dislocation of the metacarpophalangeal joint and subluxation of the carpometacarpal joint of the thumb [4].

Anatomy and physiopathology of the TMC joint have been studied several times. Comparable to two reciprocally opposed saddles whose transverse axes are perpendicular, stability of the TMC joint in power pinch and power grasp depends on the TMC joint's two prime stabilizers, the volar beak of the thumb metacarpal and the dorsal radial ligament complex [5]. According to Bettinger et al., there are at least 16 ligaments around TMC joint [6], of which the authors stress 4 important constant ligaments: volar (anterior oblique), intermetacarpal, dorsal-radial, and dorsal oblique (posterior oblique) $[5,6]$. In the final phase of opposition screw home torque rotation of the volar beak of the thumb metacarpal in the pivot area of the trapezium recess and tension on the dorsal ligament complex create stability for power pinch and power grip [5].

It is generally admitted that the mechanism of acute TMC joint dislocation is axial compression on a flexed thumb metacarpal, driving the metacarpal base out dorsally. But a second force is driven into the first web space of the thumb, which separates the base of the first and second metacarpal joints and produces a TMC joint dislocation as for cycle drivers. Mechanical instability for the TMC joint in the thumb is an important factor, which may lead to osteoarthritis of the TMC joint. The complex ligamentary system explains why there is no single good surgical technique for ligament reconstruction, but several satisfactory alternatives. 
Our case reports limits of conservative treatment for recurrent TMC joint dislocation. Furthermore, this case illustrates the necessity of open reduction after failure of conservative treatment, even in case of early failure. Finally it underlines the need for ligamentous repair to prevent concerning late recurrence of TMC dislocation or for chronic instability.

\section{CASE REPORT}

An eight-year-old left-hand-dominant girl consulted at our centre for recurrent dislocation of her left thumb. She presented no sign of hyperlaxity. She did not have familial history of laxity, nor trapezium dysplasia. Her controlateral TMC joint was stable and painless. Eight months before, she fell down from her bed and suffered from an acute trapeziometacarpal dislocation of her left hand (Figure 1). She was treated in another center. The dislocation was reduced and immobilized in a gauntlet cast. Fifteen days later, x-rays showed joint subluxation (Figure 2) and an operation was performed with closed reduction and intermetacarpal pinning. Stabilization was achieved by our colleagues with only one intermetacarpal K-wire (Figure 3). Six weeks later, the pins were removed and the TMC joint seemed to be reduced on Xrays (Figure 4). She felt no more pain. Four months later, after a new fall on her left hand, she sustained a second trapeziometacarpal dislocation (Figure 5). New x-rays showed reduced TMC joint in the cast after closed reduction (Figure 6). But after cast removal, she continued to be in pain and she complained of thumb instability. Her parents decided to consult at our center. She presented a volar palpable deformity at the base of the left thumb associated with the TMC joint dislocation recurrence. Pain was elective at palpation around TMC joint and the thumb strength of opposition was painful and clumsy. Opposition score according to Kapandji was 8/10, whereas retropulsion score according was 3/4. Clinical testing revealed a Tillaux's sign corresponding to a piano key with 'dinner fork' type deformity. The diagnosis was confirmed on Kapandji views including true incidences of AP and lateral views of the TMC in compliance with strict criteria of realization [7]. Magnetic resonance imaging (MRI) showed posterolateral ligamentous complex damage and no growth plate injury (Figure 7). 
We decided to perform open reduction and internal stabilisation of the TMC joint according to Eaton-Littler operative technique [8]. Articular inspection showed no interposed ligament or articular capsule. Radial half of the flexor carpi radialis (FCR) was passed through a drill hole in the base of the first metacarpal bone (Figure 8). In our paediatric case, it was necessary to carefully respect the growth plate at the base of the first metacarpal. Peroperative $\mathrm{x}$-rays helped us to avoid this area and allowed us to work in a safe space distant to the growth plate. Because of tightness of proximal epiphysis we chose to perform the tunnel in proximal metaphysis slightly distal to the growth plate. The radial half of the FCR was then placed beneath the abductor pollicis longus and then passed around the remaining flexor carpi radialis and secured over the dorsal capsule (Figure 9). Stabilization of the TMC joint was performed with pinning according to Iselin [9] and protected by a gauntlet for five weeks. The gauntlet and percutaneous K-wires were removed five weeks later.

At the last follow up, 12 months after the last surgery, the patient felt no more pain. Her left thumb was stable and she did not complain about lost of strength in her left hand. Opposition score according to Kapandji was 10/10, whereas retropulsion score according was 4/4. MRI showed no growth plate arrest (Figure 8).

\section{DISCUSSION}

Acute dislocation of the TMC joint is uncommon in children and clinical diagnosis is often difficult. Inspection may reveal shortening and adduction of the thumb. Kapandji view radiographs, often revealing loss of articular congruence, can be difficult in paediatric practice because of incomplete ossification of the first metacarpal base. In these less obvious situations, TMC joint reduction should be assessed by the central axis of the first metacarpal which must cross the center of the trapezium on both views, as shown in figures 3,4 and 6 . Radiographs may overlook spontaneous reduction of an acute dislocation or even minor forms of dislocation. Difficulty of reduction may also be due to incarceration of an osteochondral fragment or a ligament avulsion with a small undetected bony fragment, as for Bennett's fracture where a proximal metacarpal fragment remains attached to the volar oblique ligaments, or for Rolando multifragmented fracture. The rarity of TMC joint dislocation 
may be due to the higher incidence of fracture of the proximal first metacarpal. In cases of doubt, dynamic testing with fluoroscopy is helpful in looking for instability in different positions. As well as ultrasonography is particularly relevant as a dynamic assessment to estimate articular alignment.

There is some controversy regarding which treatments are optimal for pediatric TMC joint dislocation. The treatments have ranged from a closed or open reduction and $\mathrm{K}$ wire fixation, with or without capsuloligamentary complex reconstruction. Closed reduction and cast immobilization should be attempted. We think cast immobilization should be in place for 6 rather than 4 weeks, because of the absence of risk of stiffness in children. But conservative treatment should be controlled by X-rays every week during the first 21 days. The first recurrence for this young patient was early. According to Simonian and Trumble, closed reduction and percutaneous K-wire should be reserved to the rare case of early failure of conservative treatment, with secondary perfect reduction by manipulations [10]. That is what was performed by our colleagues. For all other situations, open reduction is required to extricate interposition soft tissue. It is possible to resort to arthroscopically inspection in adults, which allows to extricate interposition and authorize surgeon to perform capsular shrinkage. Moreover arthroscopy allows to identify exactly injured ligamentous fascicule and guides ligamentous reinsertion [11]. However we think such a technique does not find its place in an eight-year-old child. Even if arthroscopic equipment is nowadays available in children surgery, there is a risk of injuring the growth plate, especially during TMC joint surgical approach. Furthermore, considering the tightness of the workspace, transphyseal ligamentoplasty would risk to induce epiphysiodesis.

Percutaneous K-wire fixation can be classically realized according to Wagner with one transarticular pinning [12], or to Iselin, with 2 intermetacarpal K-wires [9]. Our patient was secondarily treated by our colleagues with closed reduction and percutaneous pinning intermetacarpal fixation with only one K-wire. We want to point out the necessity of double pinning to prevent rotation or even pin breakage. The first pin provides TMC reduction in the 2D plane, and the second pin allows for definitive stabilization in 3D. We prefer intermetacarpal pinning as a way of avoiding to cross growth plate for children. However, as it was stressed by Iselin, it seems to us 
important not to perforate but to embrace the fourth cortical through metacarpal pinning to prevent secondary displacement [9]. This was not respected by our colleagues and could have been responsible of defective ligamentous healing.

While first recurrence could have been considered as early failure, second injury should have been considered as late failure, probably arising by preliminary ligamentous distension. This justifying ligament reconstruction. Moreover, in case of recurrent dislocation, it is logical to inspect TMC joint to extricate any interposed ligament or capsule either open or arthroscopically. This should have been considered and therefore open reduction and ligament reconstruction should have been performed instead of a second conservative treatment attempt. Open reduction should have been performed and capsular or ligamentous injuries should have been repaired and protected by K-wires [13]. During the second surgery, where we performed open reduction, articular inspection showed no interposed ligament or articular capsule. This could be in favour of recurrent dislocation by defective ligamentous healing.

Finally, some authors proposed early ligamentoplasty, including the same techniques as for chronic TMC dislocation. They assessed that the first TMC joint dislocation is always responsible of defective ligaments healing leading consistently to recurrent dislocation or chronic dislocation [13]. We think that early ligamentoplasty should be performed in case of real post reduction instability, irreducible dislocation with capsulo-ligamentory interposition or for recurrent dislocation during conservative treatment. Chronic TMC dislocation is very rare in children. Therefore trapezium dysplasia or lack of reduction by preliminary acute TMC dislocation with interposed tissue must be excluded in these situations. Different techniques are proposed for ligament reconstruction. Those commonly used are described by Eaton and Littler, Brunelli et al and Péquignot et al.. Eaton and Littler proposed to use half the FCR with maintain of its distal insertion on the base of the second metacarpal to reconstruct the intermetacarpal ligament which is usually damaged in posterolateral TMC joint instability [8]. Besides volar ligament reconstruction, this techniques allows to perform dorso-radial capsulo-ligamentory reinforcement. Indeed after perforating metacarpal bone, half the FCR surrounds the base of the first metacarpal and crosses under the Abductor Pollicis Longus (APL) tendon before to suture itself. Brunelli et al. suggested taking a half APL bipolar transfer on the palmar base of the 
first and second metacarpal, where the axis of the transferred tendon is parallel to the nail plan, and supposed to supplant volar oblique ligament failure [14]. This techniques is not appropriated to treat dorso-radial ligamentory failure. It consists to perform volar intermetacarpal ligament reconstruction without dorso-radial ligamentory reconstruction or reinforcement. These two techniques consist of volar ligament reconstruction, whereas Péquignot et al. proposed only dorsal capsuloligamentory reinforcement with tongue of the Extensor Carpi Radialis Longus used as a reflection pulley to dorsalize APL [15]. This technique is above all capsuloligamentory support rather than ligamentory reconstruction.

Our young patient presented posterolateral instability with recurrent TMC joint dislocation. We attempted to restore intermetacarpal ligamentory system combined with dorso-radial capsulo-ligamentory reinforcement. It leads us to treat her with Eaton-Littler ligamentoplasty using half the FCR (Figure 9). Because of the growth plate at the base of the first metacarpal, the tunnel should avoid the epiphyseal cartilage. We chose to perform the tunnel in proximal metaphysis distal to the growth plate. If proximal epiphysis is wide enough we think that it is also possible to drill hole proximal to the growth plate (Figure 8). Our case showed no growth plate arrest at the last follow-up, but a longer follow-up is mandatory to assess long-term consequences of the transferred tendon on growth of the first metacarpal. Whatever the type of treatment for TMC joint reduction, it seems to us important to associate an intermetacarpal or TMC-K-wire pinning with 6 weeks immobilization in a gauntlet, especially in paediatric traumatology with young restless patients. Furthermore, it is really important not to forge the tunnel for the ligamentoplasty cross the growth cartilage. Except for these features, the proposed care is identical to that appropriate for the adult TMC joint. 


\section{FIGURES}

Figure 1: Radiographs showing first TMC joint dislocation (arrows).

Figure 2: Secondary displacement of the TMC joint after 15 days of gauntlet. TMC joint is dislocated again (arrows).

Figures 3: Radiographs after surgical percutaneous treatment with K-wire. TMC joint is in a reduced position.

Figure 4: Radiographs after K-wire removal. TMC joint is in a reduced position.

Figure 5: Radiographs after second accident with second TMC dislocation. There was no osteochondral fragment (arrows).

Figure 6: Radiographs of second orthopedic treatment with gauntlet just before removal of the cast showing reduced TMC joint (arrows).

Figure 7: Preoperative MRI of the TMC joint profile. Arrows point to the capsuloligamentous complex damage.

Figure 8: Postoperative MRI of the TMC joint. There was no growth plate arrest. Arrows point to the drill hole in the base of the first metacarpal bone.

Figure 9: Postoperative MRI of the TMC joint showing the course of the ligamentoplasty through the first metacarpal (arrows).

\section{DISCLOSURE}

The authors declare that they have no conflicts of interest, no financial interests in this research project or in any of the techniques or equipment used in this study. 


\section{BIBLIOGRAPHY}

1. Mueller JJ. Carpometacarpal dislocations: report of five cases and review of the literature. J Hand Surg. 1986;11:184-8.

2. McLaughlin MJ, Abouzahr MK. Acute dislocation of the trapeziometacarpal joint in a child. J Hand Surg. 1998;23:1097-9.

3. Varitimidis SE, Sotereanos DG. Palmar oblique ligament reconstruction for carpometacarpal joint dislocation in an 11-year-old: a case report. J Hand Surg. 1999;24:505-7.

4. Rashdeen FMN, Manohar A, Pathmanathan V. Simultaneous dislocation of the metacarpophalangeal and subluxation of the carpometacarpal joints of the thumb in a child. Med J Malaysia. 2005;60:117-8.

5. Edmunds JO. Traumatic dislocations and instability of the trapeziometacarpal joint of the thumb. Hand Clin. 2006;22:365-92.

6. Bettinger PC, Smutz WP, Linscheid RL, Cooney WP, An KN. Material properties of the trapezial and trapeziometacarpal ligaments. J Hand Surg. 2000;25:1085-95.

7. Kapandji A, Moatti E, Raab C. Specific radiography of the trapezo-metacarpal joint and its technique. Ann Chir. 1980;34:719-26.

8. Eaton RG, Littler JW. Ligament reconstruction for the painful thumb carpometacarpal joint. J Bone Joint Surg Am. 1973;55:1655-66.

9. Iselin $\mathrm{M}$, Blanguernon $\mathrm{S}$, Benoist $\mathrm{D}$. Fractures de la base du premier métacarpien. Mém Académie Chir Fr. 1956;82:771-4.

10. Simonian PT, Trumble TE. Traumatic dislocation of the thumb carpometacarpal joint: early ligamentous reconstruction versus closed reduction and pinning. J Hand Surg. 1996;21:802-6.

11. Badia A. Arthroscopy of the trapeziometacarpal and metacarpophalangeal joints. $\mathrm{J}$ Hand Surg. 2007;32:707-24.

12. Wagner CJ. Method of treatment of Bennett's fracture dislocation. Am J Surg. 1950;80:230-1.

13. Liverneaux PA, Ichihara S, Hendriks S, Facca S, Bodin F. Fractures and dislocation of the base of the thumb metacarpal. J Hand Surg Eur Vol. 2014

14. Brunelli G, Monini L, Brunelli F. Stabilisation of the trapezio-metacarpal joint. J Hand Surg Edinb Scotl. 1989;14:209-12.

15. Péquignot JP, Giordano P, Boatier C, Allieu Y. Traumatic dislocation of the trapeziometacarpal joint. Ann Chir Main. 1988;7:14-24. 


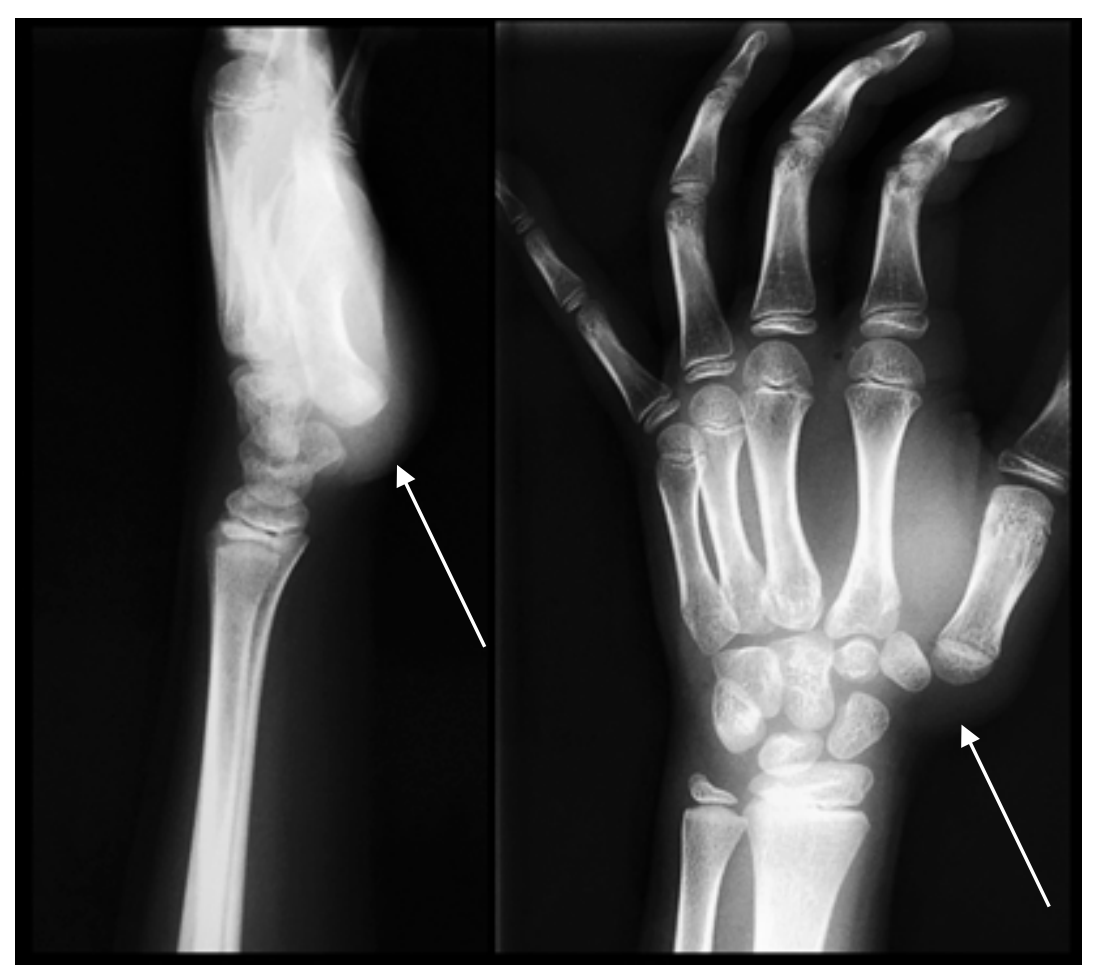

Figure 1 


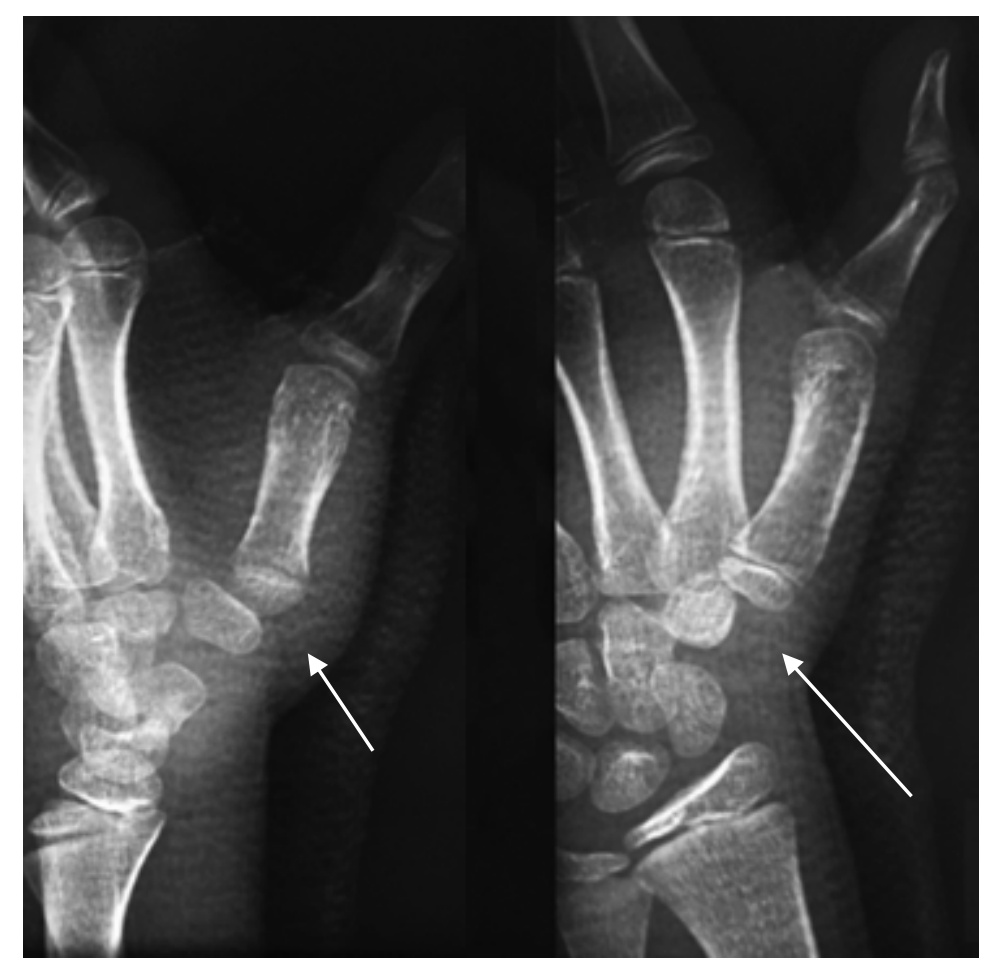

Figure 2 


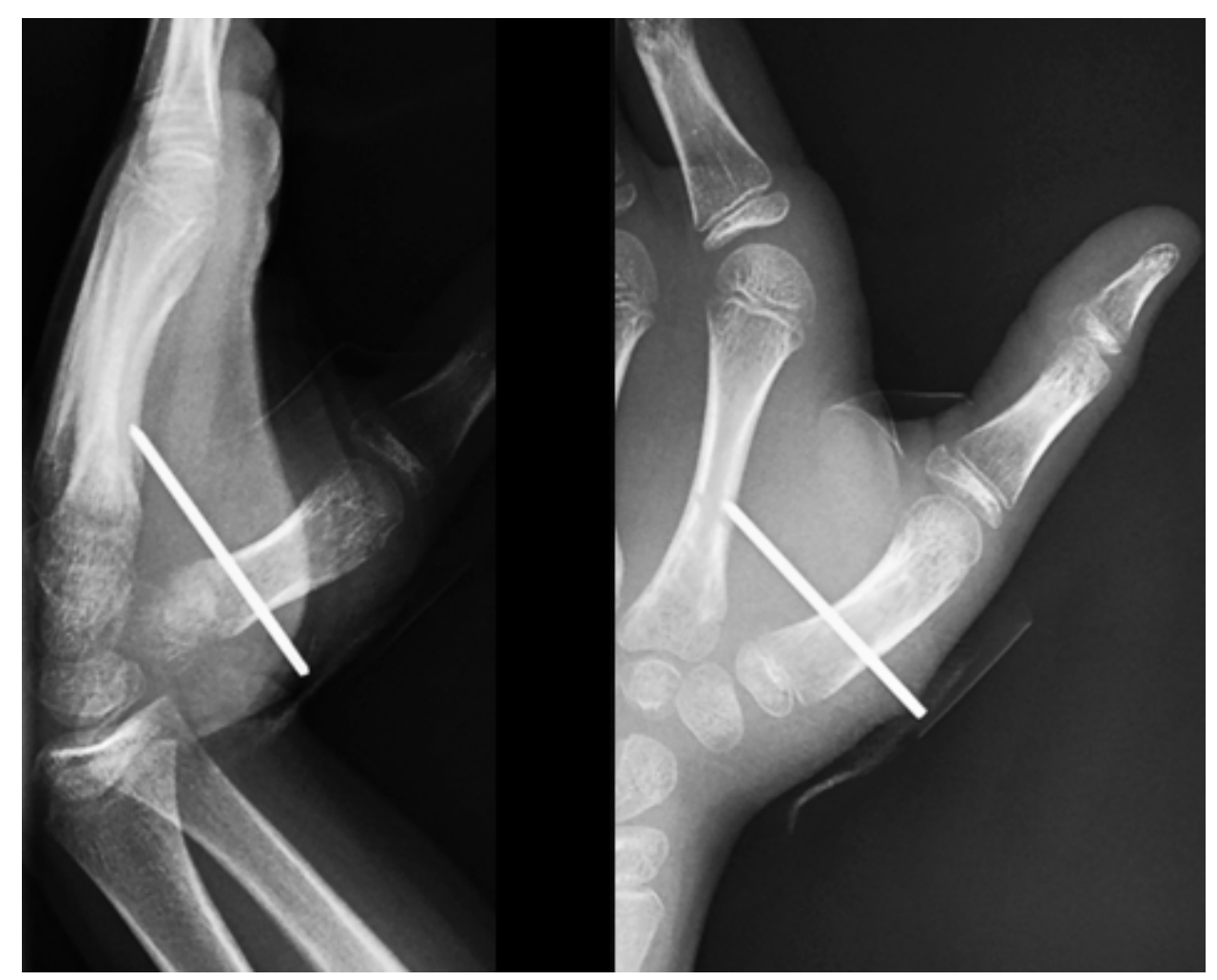

Figure 3 


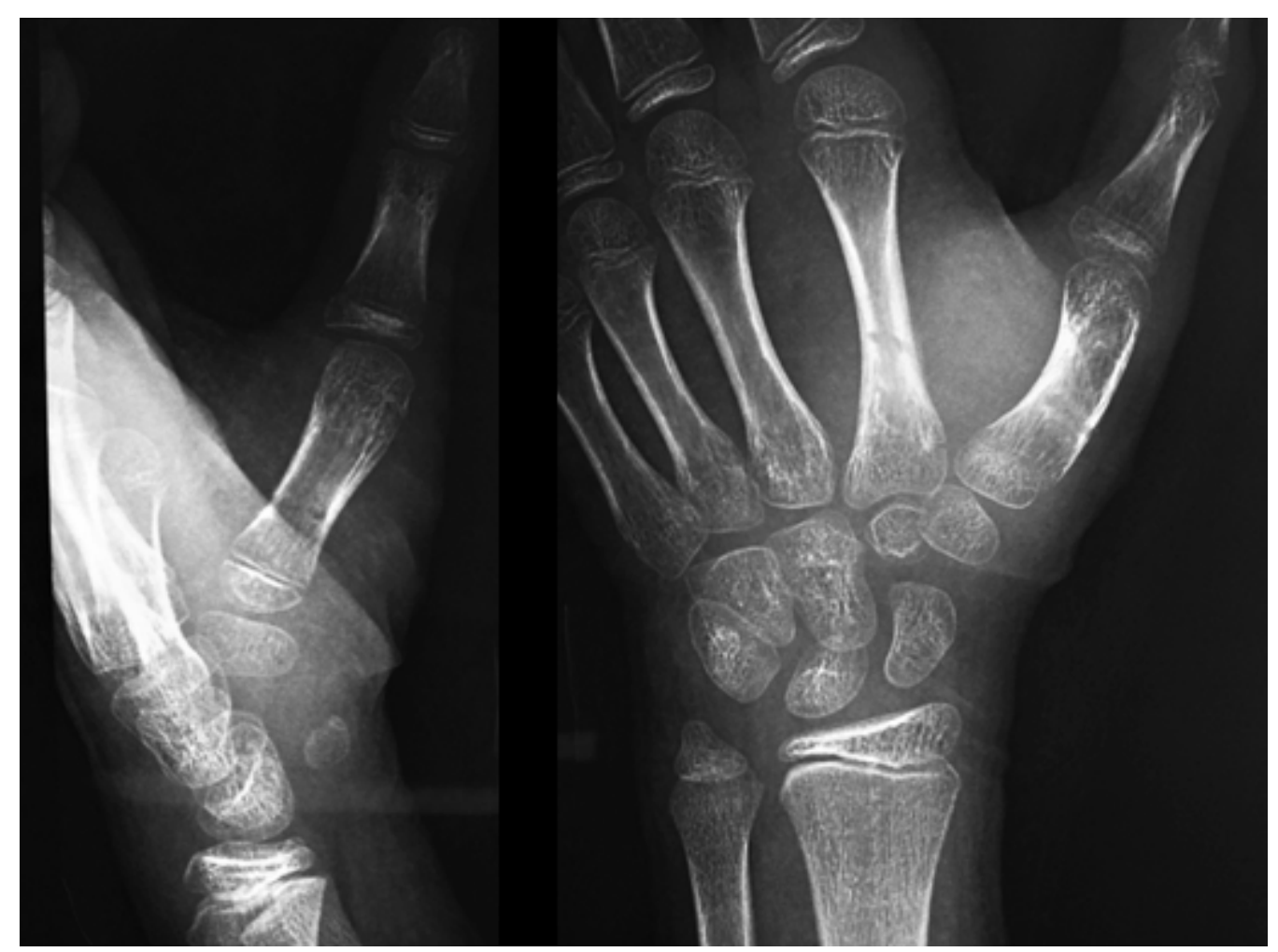

Figure 4 


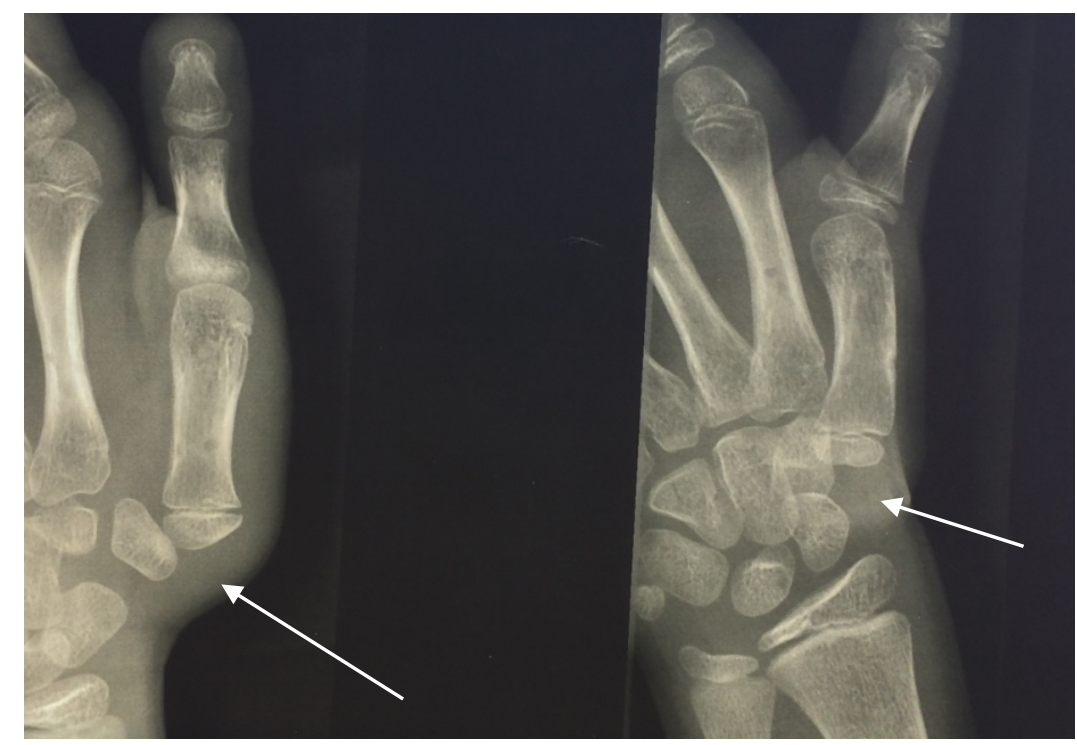

Figure 5 


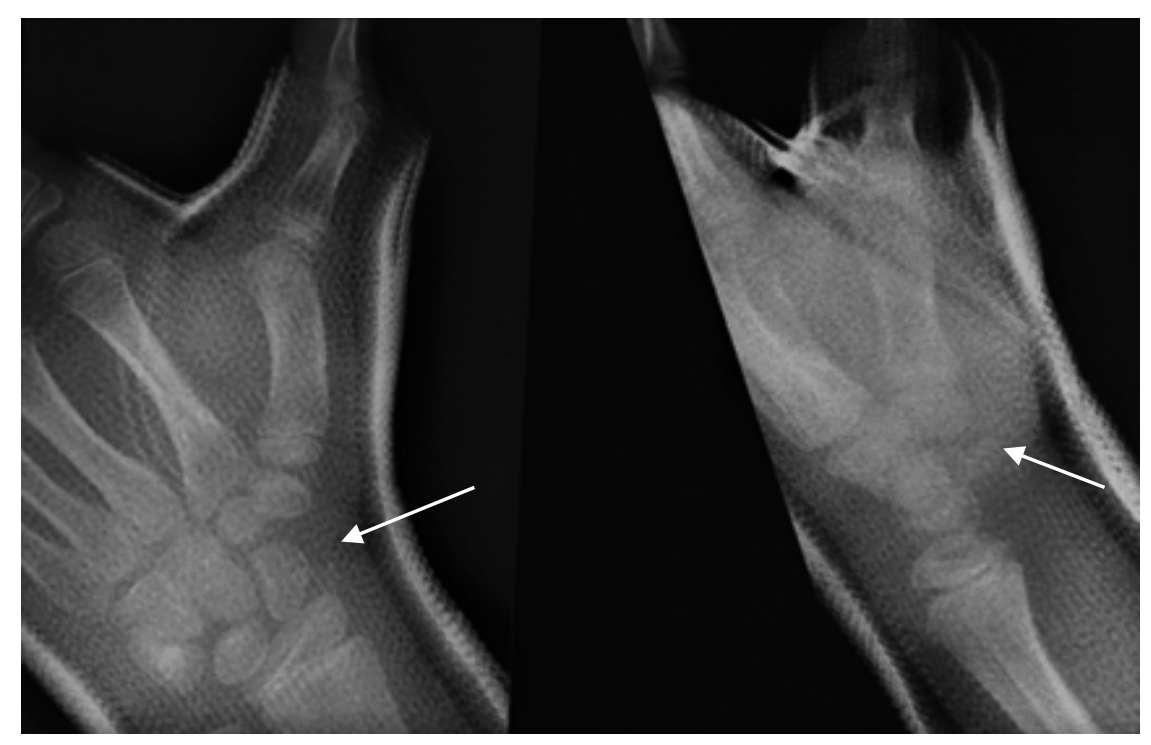

Figure 6 


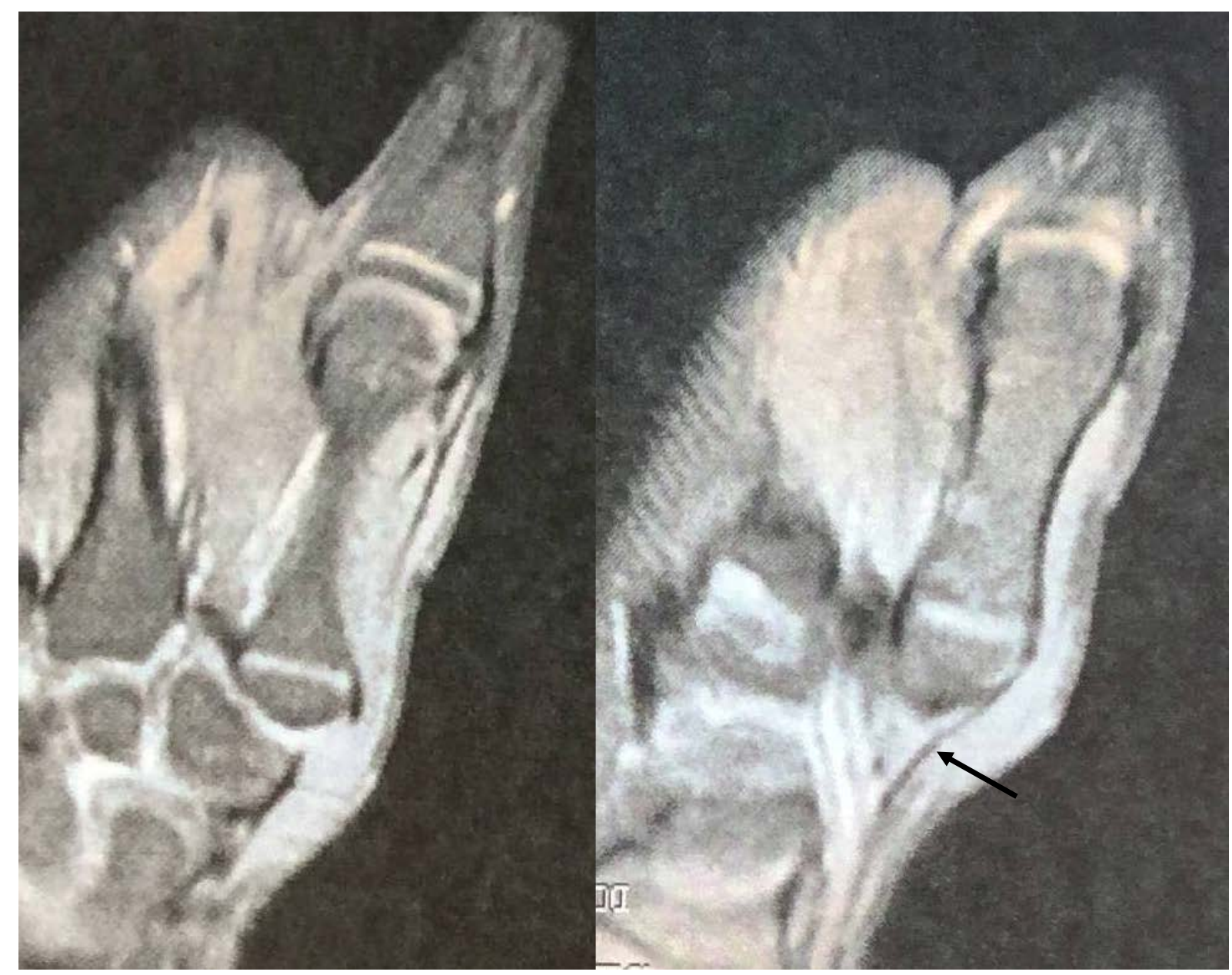

Figure 7 


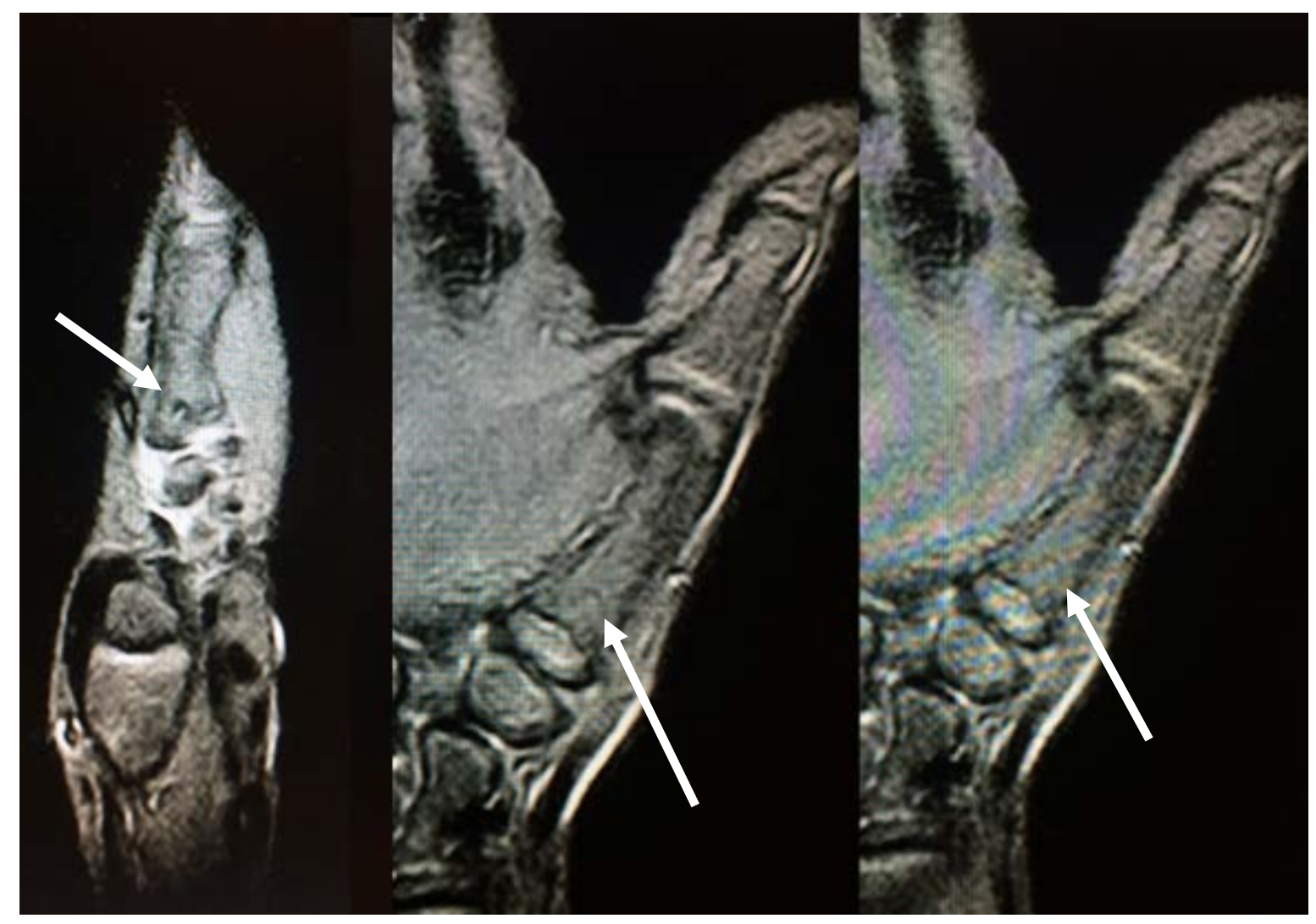

Figure 8 


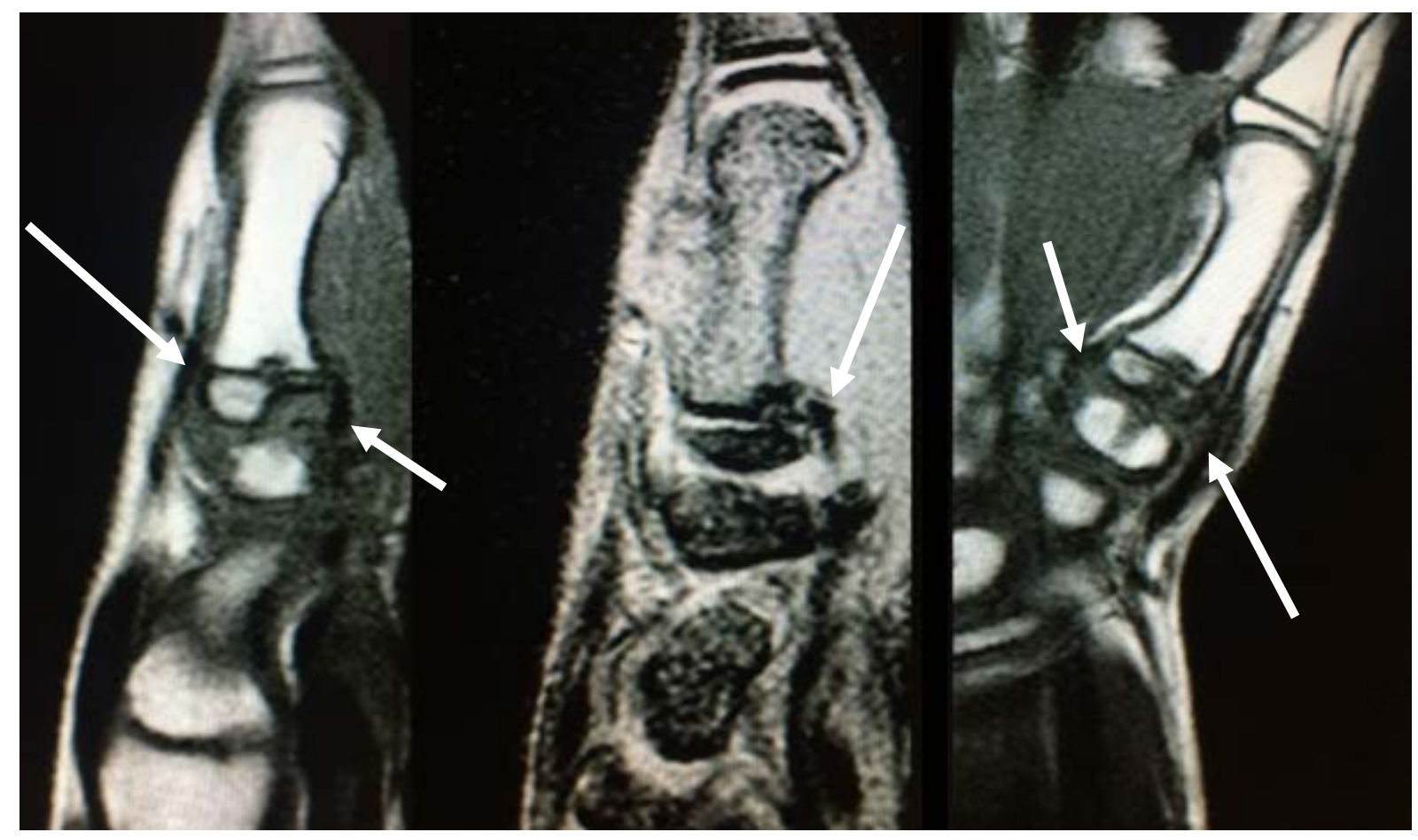

Figure 9 